\title{
Inter and Intra-rater reliability and validity of an instrument made in rural set up to measure Maximum Inspiratory Pressure termed as Dhiraj Maximum Inspiratory Pressure Device
}

\author{
Rasal Sarvesh $V^{1}$, Diwate Abhijit $D^{2}$, Anap Deepak $B^{3}$
}

1. MPT 2nd yr. Cardio-Vascular \& Respiratory Sciences PT DVVPF's College of Physiotherapy Ahmednagar, Maharashtra, India.

2. Prof \& HOD Dept. of Cardio-Vascular \& Respiratory Sciences PT DVVPF's College of Physiotherapy, Ahmednagar, Maharashtra, India.

3. Prof \& HOD Dept. of Musculoskeletal Sciences PT DVVPF's College of Physiotherapy, Ahmednagar, Maharashtra, India.

\section{Abstract}

Background: Maximum Inspiratory Pressure (MIP) measures inspiratory force generated by respiratory muscles. MIP is measured with a non-invasive pressure transducer device which has a mouthpiece, pressure gauge, and dial showing readings. Respiratory muscle weakness is a common sign depicted in conditions like neuromuscular disorders, cardiovascular disease, and other respiratory pathologies which affect the individual's lung volume and capacity. The devices available in the market to measure the MIP are costly. Aim: This study was undertaken to find out inter-rater and intra-rater reliability and validity of the therapist made an instrument in rural set up to measure maximum inspiratory pressure (DMIPD). Method: This cross-sectional study was carried out in 40 normal healthy individuals without lung diseases were recruited as per inclusion criteria. MIP values were noted by two raters using the DMIPD and were then compared between two rater values to that of the gold standard values. Validity and reliability were calculated using interclass correlation coefficients (ICC) and p-value. Result: Statistical analysis for inter-rater reliability by Kappa using SPSS 1.000 showing almost perfect agreement as per Kappa interpretation also for intra-rater analysis an ICC value of 0.96 depicting excellent validity and Cronbach alpha value of 0.97 thereby proving it to have excellent reliability. Conclusion: We conclude that DMIPD has excellent reliability and validity.

KEYWORDS: Maximum Inspiratory Pressure; ICC; Reliability; Validity, Cronbach alpha.

\section{INTRODUCTION}

$\mathrm{M}$ aximum Inspiratory Pressure (MIP) is the most widely used non-invasive method of diagnosing inspiratory muscle weakness [1]. MIP is a valid and reliable method, as proven by many studies for the measurement of respiratory muscle strength. MIP measurements were taken from Residual Volume (RV) or Functional Residual Capacity (FRC) [1-4]. MIP instrument is portable and easy to administer in all ages and gender. The main advantage of this method is that it can be used in any patient who can understand and follow the command. In order to understand the severity of strength impairment in patients with chronic pulmonary diseases along with many different conditions like chronic kidney disease (CKD), Heart failure, Cerebrovascular accident patients (CVA), MIP device can be used for assessment of MIP without any harm to the patient [4-7]. MIP reflects not only the level of functioning of the lungs but also the elastic recoiling property of the lungs and chest wall as

Correspondence: Dr. Rasal Sarvesh Vivekanand. (PT), Shree Pooja Shreeram Housing Society Kedgaon Devi Road, Ahmednagar, Maharashtra, India. Email id: rasal.sarvesh5@gmail.com

\begin{tabular}{|ll} 
& \\
eISSN: 2395-0471 & C Authors; 2020. (CC BY-NC-SA 4.0) \\
pISSN: 2521-0394 & This is an Open Access article which permits unrestricted \\
DOI: 10.31878/ijcbr.2020.63.04 & non-commercial use, provided the original work is properly cited.
\end{tabular}


well [8]. In the market the established devices which are available like MICRORPM respiratory muscle testing device is cost around $\$ 1,263$ [9]. As the tools are not cost-efficient, we designed a therapist made cost-efficient MIP device (DMIPD). To ensure that the device we created generates accurate results as that of the available standard device, the aim of the study was to find out the validity and reliability of this device.

\section{Material And Methodology}

Ethics approval: Ethical approval was obtained from the institutional ethical committee of our institute

Inclusion criteria: Participants are between the age group of 20-60 years. Participants who selfreported as healthy individuals without known lung disease and gave written informed consent for the study with the willingness to participate were recruited for the study.

Exclusion criteria: Participants with chronic diagnosed respiratory or cardiovascular diseases, neurological diseases, and psychological problems, unable to understand instructions, and those who were unable to complete the test were excluded from the study.

Sample size: Fifty participants selected from the community for participation in the study, a total of 10 participants, could not complete the study, the reason being five participants unable to understand, and while five were unable to complete the test.

Sampling method: Recruited using purposive sampling

Methodology: Participants were instructed in a quiet room for a better understanding of the testing procedure. The participants were in an upright sitting position on a chair with back support and foot resting on the ground, as shown in figure one. The procedure for performing the test was demonstrated by the therapist to all participants in the language best understood by them. The participants were asked to take a deep breath through the mouthpiece and hold for $1 \mathrm{sec}$. Three readings were taken with a $5 \mathrm{~min}$ interval between each reading. MIP values were noted twice each by two raters using the self-made cost-effective hand-held vacuum manometer instrument (DMIPD) with an interval of $5 \mathrm{~min}$ between each measurement. The same procedure was repeated on the second day with the second therapist after an interval of $24 \mathrm{hr}$ from the first reading was taken. The DMIPD consists of a vacuum manometer with a flexible tube attached to the mouthpiece. The manometer consisted of an $83 \mathrm{~cm}$ long connecting tube between the analogue dial and $5 \mathrm{~cm}$ stainless steel mouthpiece, as shown in figure two. The therapists were blinded for readings. The readings from two raters then compared between two rater values to that of the gold standard values. Validity and reliability were measured using interclass correlation coefficients (ICC) and p-value.

\section{Study Flow Chart:}

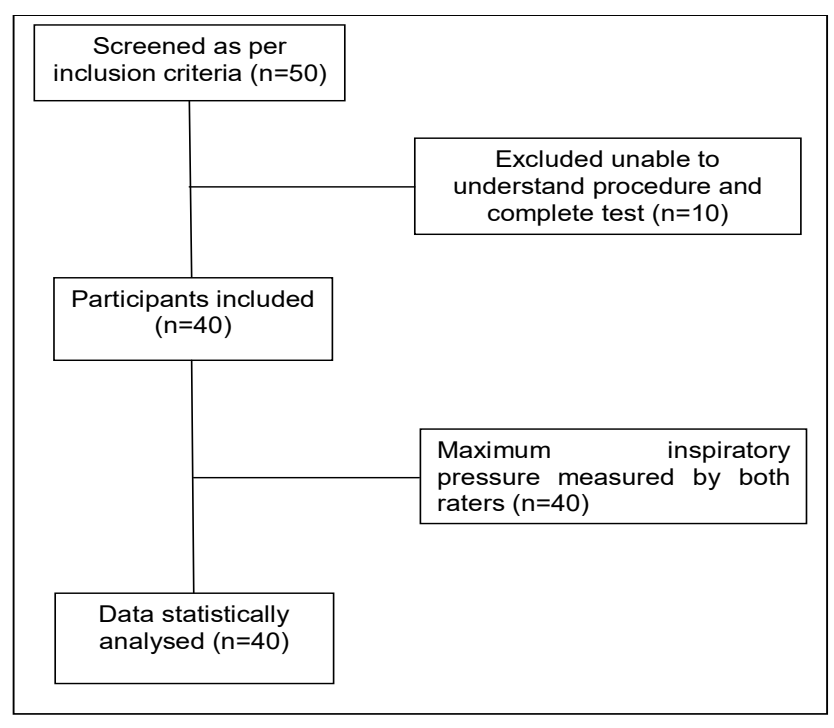

Statistical analysis: Analysis was done with SPSS software for inter-rater reliability by Kappa method, Chronbach's Alpha values were obtained for reliability; Intra-rater analysis was done by using ICC value. Kappa result is interpreted as follows: values $\leq 0$ as indicating no agreement and $0.01-0.20$ as none to slight, $0.21-0.40$ as fair, $0.41-0.60$ as moderate, $0.61-0.80$ as substantial, and $0.81-1.00$ as almost perfect agreement. In the present study, the significance level was set at 0.005. Statistical analysis shows for inter-rater reliability by Kappa using SPSS 1.000 showing almost perfect agreement as per Kappa interpretation [10,11].

\section{Results}

Table 1 summarizes the Intra-rater analysis of the ICC value of 0.96 depicting excellent validity and Cronbach alpha value of 0.97 ; thereby proving the DMIPD to have excellent reliability.

Table 1: Reliability statistics

\begin{tabular}{|c|c|c|}
\hline $\begin{array}{c}\text { Chronbach's } \\
\text { Alpha }\end{array}$ & $\begin{array}{c}\text { Chronbach's } \\
\text { Alpha Based on } \\
\text { standardized items }\end{array}$ & $\begin{array}{c}\text { Number } \\
\text { of items }\end{array}$ \\
\hline .971 & .973 & 4 \\
\hline
\end{tabular}

Table 2. summarizes the analysis of ICC value; we found ICC 0.986 and p-value 0.000 , which is significant. 
Table 2. Interclass correlation coefficient

\begin{tabular}{|c|c|c|c|c|c|c|c|}
\hline & \multirow{2}{*}{$\begin{array}{c}\text { Interclass } \\
\text { correlation }^{\mathrm{b}}\end{array}$} & \multicolumn{2}{|c|}{$95 \%$ confidence interval } & \multirow[t]{2}{*}{ value } & \multirow[t]{2}{*}{ df1 } & \multirow[t]{2}{*}{ df2 } & \multirow[t]{2}{*}{ Sig } \\
\hline & & Lower bound & Upper bound & & & & \\
\hline Single measures & $.885^{a}$ & .820 & .931 & 34.194 & 39 & 117 & .000 \\
\hline Average measures & $.968^{\mathrm{c}}$ & .948 & .982 & 34.194 & 39 & 117 & .000 \\
\hline \multicolumn{8}{|c|}{$\begin{array}{l}\text { Note: Two-way effects model where people's effects are random and measure effects are fixed. }{ }^{a} \text { The } \\
\text { estimator is the same, whether the interaction effects is present or not. }{ }^{b} \text { Type A interclass correlation } \\
\text { coefficients using an absolute agreement definition. 'This estimate is computed assuming the } \\
\text { interaction effect is absent because it is not estimable otherwise. }\end{array}$} \\
\hline
\end{tabular}

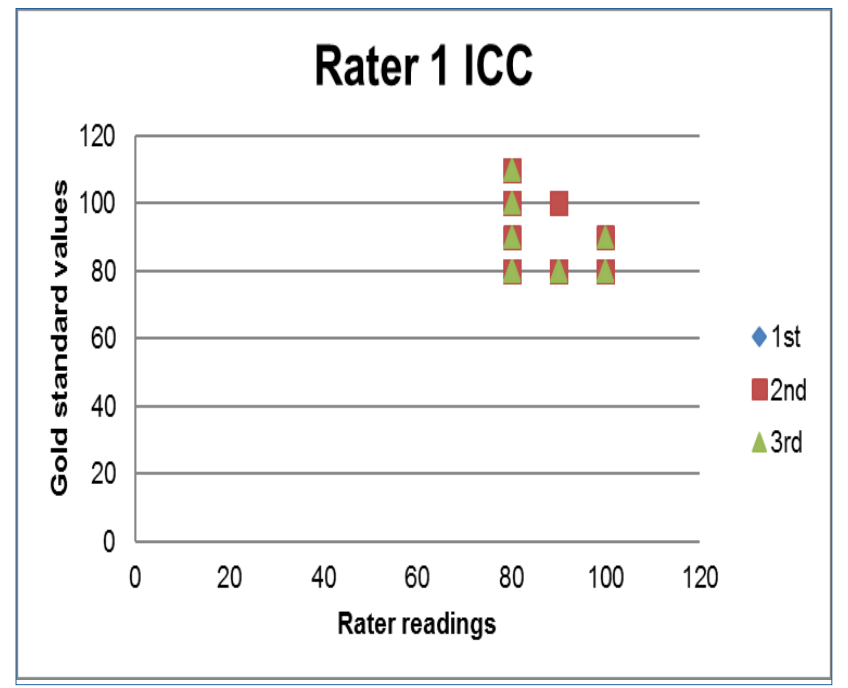

Fig 1. ICC for Rater 1

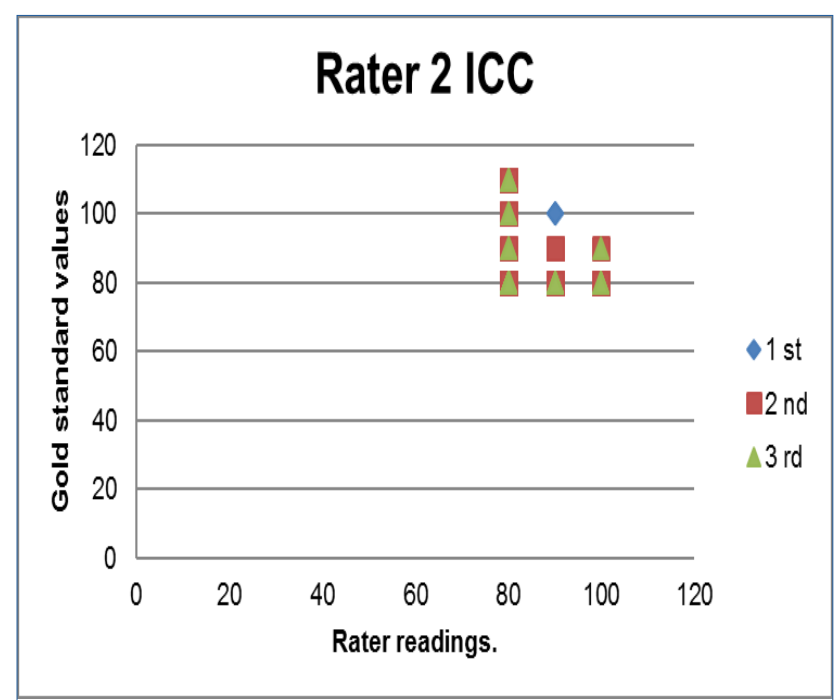

Fig 2. ICC for Rater 2

Figure 1 shows all values assessed by Rater One are close to each other hence showing more excellent ICC.

Figure 2 shows all values assessed by Rater. Two are close to each other hence showing more excellent ICC.

Figure 3 shows all values assessed by both the Raters for Intra Rater Reliability are near to each other, establishing excellent rater reliability.

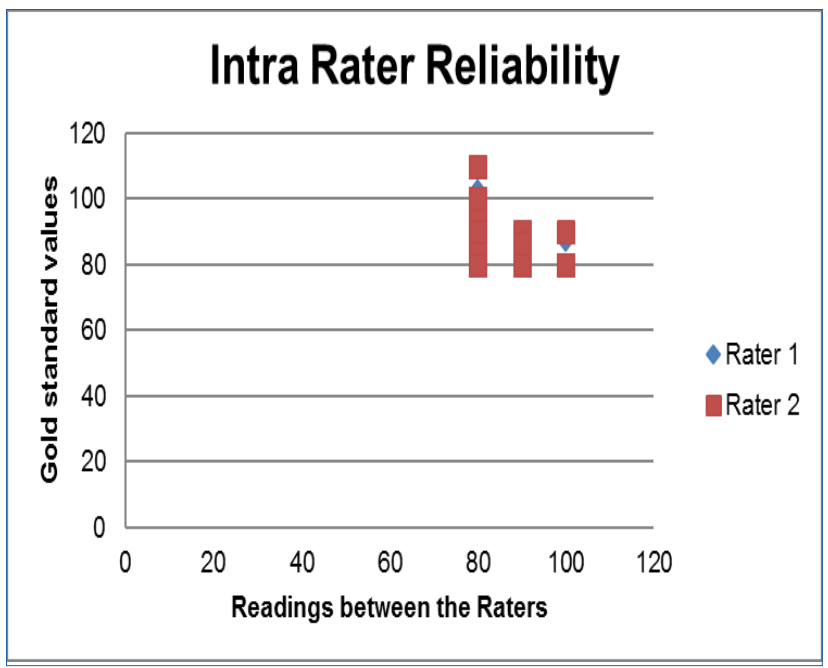

Fig 3. Intra Rater Reliability

\section{Discussion}

This study was aimed at evaluating Interrater, Intra-rater reliability, and Validity of DMIPD for measuring the Maximum Inspiratory Pressure (MIP). MIP is the easiest, reliable, noninvasive, simple way to measure the strength of respiratory muscle from which the therapist or clinician gets an idea about the affection of pulmonary functions [12]. For Inter and Intrarater reliability, the MIP readings were taken and compared with standard values [13-16]. ICC values were also analyzed for the validity of the instrument. As per interpretation of ICC value done by Koo TK et al. in a study titled "A guideline of selecting and reporting interclass correlation coefficients for reliability research," an ICC value higher than 0.90 indicate excellent reliability [17]. DMIPD measures the maximal inspiratory pressure in a similar way; the established MIP device measures the maximum inspiratory pressure. These findings are verified with statistical analysis of the data. In a study done by Torres-Castro $\mathrm{R}$ et al. on an agreement between clinical and nonclinical digital manometer for assessing maximal respiratory pressures in healthy subjects, mentions that in most low and middle-income countries, electronic transducer or digital manometers are not widely 
used because the cost is a major limiting factor for the use of digital devices in many regions [18]. He further analyzed industrial nonclinical manometer with commercial clinically-validated manometer to determine the degree of agreement between two hand-held digital manometers and concluded that nonclinical digital manometers could accurately measure maximal respiratory pressure, as demonstrated in healthy individuals with a parallel measurement approach.

As evidence suggests, industrial instruments can be used for clinical diagnosis as they can be readily available at low cost. Instruments can be validated to minimize errors during assessments, and reliability should be assessed for internal consistency to ensure the accuracy of readings [19]. Clinical devices available for diagnosis are expensive, and the use of these devices depends on the availability and the cost of the instruments. We can use industrial devices which are cost-efficient and can be validated for medical diagnostic purpose. The DMIPD made with a hand-held portable Vacuum manometer is calibrated as per industrial standards and has readings displayed in $\mathrm{mmHg}$, which is costeffective (Rs.400/- INR). This MIP device is a good measure of Maximum inspiratory pressure, but its measurement also depends on the understanding of the individual and skills of the therapist or clinician to carry out the test. The efficacy of the test totally depends on the skills of the therapist to administer the test, knowledge, and understanding of the subject/patient about the test. In the present study, data analyzed for rater reliability and validity has found that the device has excellent reliability and validity; it is cost-effective and can be used in any setup.

\section{Conclusion}

The hand-held portable DMIPD device has excellent reliability and validity. It is costeffective can be used in any community setup to measure the Maximum Inspiratory Pressure.

Acknowledgment: I am thankful to Dr. Archana Nagargoje ma'am for helping me in the study and grateful to my colleagues.

\section{Conflict of interest : Nil}

Source of funding : Nil

\section{REFERENCES}

1. Polkey MI, Green M, Moxham J. Measurement of respiratory muscle strength. Thorax. 1995; 50(11):1131.

2. Caruso $P$, Albuquerque AL, Santana PV, Cardenas LZ, Ferreira JG, Prina E, Trevizan
$\mathrm{PF}$, Pereira MC, Iamonti V, Pletsch R, Macchione MC. Diagnostic methods to assess inspiratory and expiratory muscle strength. Jornal Brasileiro de Pneumologia. 2015;41(2):110-23.

3. European RS, American Thoracic Society. ATS/ERS Statement on respiratory muscle testing. American journal of respiratory and critical care medicine. 2002; 166(4):518.

4. Khalil M, Wagih K, Mahmoud O. Evaluation of maximum inspiratory and expiratory pressure in patients with chronic obstructive pulmonary disease. Egyptian Journal of Chest Diseases and Tuberculosis. 2014; 63(2):329-35.

5. Parreira VF, França DC, Zampa CC, Fonseca MM, Tomich GM, Britto RR. Maximal respiratory pressures: actual and predicted values in healthy subjects. Revista Brasileira de Fisioterapia. 2007; 11(5):361-8.

6. Pessoa I, Sclauser MB, Parreira VF, Fregonezi GA, Sheel AW, Chung F, Reid WD. Reference values for maximal inspiratory pressure: a systematic review. Canadian respiratory journal. 2014; 21(1):43-50.

7. Szeinberg A, Marcotte JE, Roizin H, Mindorff C, England S, Tabachnik E, Levison $H$. Normal values of maximal inspiratory and expiratory pressures with a portable apparatus in children, adolescents, and young adults. Pediatric pulmonology. 1987 Jul; 3(4):255-8.

8. Measurement of respiratory muscle strength; Thorax 50, 1131-1135:1995.

9. Medical Device Depot inc. [homepage on the Internet]. c2020 [updated 2020 Jul 29; cited 2020 Jul 29]. Available from: https:// www.medicaldevicedepot.com/MicroDirectMicroRPM-Pressure-Meter-p/rpm01.htm

10. McHugh ML. Interrater reliability: the kappa statistic. Biochemia medica: Biochemia medica. 2012;22(3):276-82.

11. Terry K, A Guideline of Selecting and Reporting Intraclass Correlation Coefficients for Reliability Research; Journal of Chiropractic Medicine. 2016;15: 155-63.

12. Raida I. Determinants of Maximal Inspiratory Pressure. Am J Respir Crit Care Med.1998;158:1459-64. 
13. Parreira VF, Maximal respiratory pressures: actual and predicted values in healthy subjects; Rev. bras. Fisioter.2007;11,361-8.

14. Lida Maritza G, Normal values of the maximal respiratory pressures in healthy people older than 20 years old in the city of Manizales Colombia; Colombia Médica.2012; 43:11925.

15. Karla M, Normal values for maximal inspiratory and expiratory pressures of adolescents; European Respiratory Society Annual Congress 2013.

16. Isabela MB, Reference values for maximal inspiratory pressure: A systematic review; Can Respir J. 2014;21:43-50.
17. Koo TK, Li MY. A guideline of selecting and reporting intraclass correlation coefficients for reliability research. Journal of chiropractic medicine. 2016;15(2):155-63.

18. Torres-Castro R, Sepúlveda-Cáceres N, Garrido-Baquedano R, Barros-Poblete M, Otto-Yáñez M, Vasconcello L, Vera-Uribe R, Puppo H, Fregonezi G. Agreement between clinical and non-clinical digital manometer for assessing maximal respiratory pressures in healthy subjects. PloS one. 2019;14(10):e0224357.

19. Carole L. Validity and reliability of measurement instruments used in research, Am J Health-Syst Pharm.2008;65, 2276-84. 